\title{
Business Model Innovation in Tourism: How to Survive in Highly Competitive Environments
}

\author{
Robert Ambrož \\ Advansys d.o.o., Slovenia \\ robert.ambroz@intima.si \\ Doris Gomezelj Omerzel \\ University of Primorska, Faculty of Management, Slovenia \\ doris.gomezelj@fm-kp.si
}

The objective of this research is to clarify the role and the importance of the business model in tourism and to demonstrate the necessity of changing the business model to maintain competitiveness. By employing the Osterwalder nine-block business model Canvas framework, an interview with the manager of Slovenian tourist agency was conducted. Without the innovation of individual segments of the business model or, more often the majority of its dimensions, the firm would not have survived. In our case, the necessity of innovating the business model was confirmed by the statement of the agency's manager: 'In any case, without changes, we would no longer exist on the market; without future changes, we will no longer exist on the market either.' This article presents a single case study; therefore, the results may have limited generalisability. Everyday changes in competitive markets should be met by the innovation of business models. Tourism firms must be able to articulate and innovate their business model if they want to survive in a rapidly evolving competitive global market. Although studies on business modelling are common in the tourism sector, little about them has been documented regarding the tourism sector in Slovenia. Hence, this study, which focuses on a Slovenian tourist agency, aims to fill this knowledge gap. Our case is particularly interesting, because we have demonstrated the interdependence of segments and their modification, we have shown that the business model is already present in the tourist agency, and we articulated it.

Keywords: tourism, business model, Canvas business model, innovation https://doi.org/10.26493/2335-4194.10.175-183

\section{Introduction}

Companies' external environments are changing rapidly, as are the habits and preferences of consumers. Consequently, any organisation that wants to remain competitive and survive on the market should constantly make changes in their business. The real challenge for a company is to maximise the impact of changed business, even though changes usually require resources, while the outcome of implemented changes is often uncertain. Using the proper tools can aid in being successful in this process.

Since its establishment, each organisation explicitly or implicitly possesses a business model that explains a way of creating value for the customer, the method of delivering the value to the customer, and the method of making a profit (Teece, 2010). We need to know and understand all the elements of the business model, only then can it be successfully changed (Chesbrough, 
2007). The business functions that are defined in the business model are mutually interdependent. Therefore, each time one element of the business model is changed, this mutual interdependence must be considered.

An innovative business model can play an essential role in the competitiveness of the organisation. It enables it to commercialise new ideas or technologies. Furthermore, we believe that the innovative business model itself represents a competitive advantage.

\section{Theoretical Framework}

Managers should give high priority to business model innovation, as this can help to identify sources of profits and revenues. The main research question is whether organisations in the tourism sector with the aim of achieving greater competitiveness are changing their business model and how they change it. Accordingly, the primary purpose of this paper is to (1) clarify the role and the importance of the business model in tourism, and (2) demonstrate the necessity of changing the business model to maintain competitiveness.

By employing the Osterwalder nine-block business model Canvas framework, an interview with a Slovenian tourist agency was conducted.

\section{Business Model}

Despite a growing body of literature and studies in the area of business model concepts, a consensus among scholars has not yet been reached (Yunus, Moingeon, \& Lehmann-Ortega, 2010). Regardless, after a period of a lack of a universal definition for the term 'business model,' it can be seen that the confusion in this area is decreasing and common grounds are being approached. In their study, Zott, Amit, and Massa (2010) explored the development of the concept of business model and, despite the diversity of different researchers' views, they found some common issues. First, business models are becoming a significant unit of business analysis in firms; second, business models help firms perform an integral approach when explaining how the firms operate; third, all the firms' activities are presented in the conceptualisations of the proposed business model; fourth, the business model is a great framework for explaining how value in the firm is created.

A business model explains the firm's ability to capture value. It brings the request for competitive advantage to the forefront (Casadesus-Masanell \& Heilbron, 2015). However, it is hard to find a theoretical foundation of the business model definition in economic or business studies. According to Teece (2010), there are some key facts for this situation. Economic theory assumes that business is based on tangible things. It is clear that a consumer will pay if a firm delivers value at a competitive price. Therefore, it is possible to regulate the entire process of selling by regulating prices. In accordance with this theory the intangible factors, which are also parts of the business models, are not important. The business model can come into existence before the organisation is founded. Thus, a business model exists independently of the firm, while the firm cannot exist without a business model.

As product innovation is not enough to offer sufficient competitive advantage (competitors can quickly copy innovations), business model innovation is an opportunity to build sustainable competitive advantage (Teece, 2010). The concept of the business model is simple: it is the business logic of the firm (Tikkanen, Lamberg, Parvinen, \& Kallunki, 2005; Gebauer \& Ginsburg 2003), representing the strategic positioning on the market (Yip, 2004); it is about how a firm sustains growth and creates and captures value for stakeholders (Casadesus-Masanell \& Ricart, 2010). For Timmers (1998), a business model is the architecture for the product or service, involving different business actors (partners, competitors, and customers), the presentation of resources and the description of how to make revenues. Magretta (2002) describes the business model as writing a story about the company. Moreover, it enables firms to capture value from their innovations (Chesbrough \& Rosenbloom 2002). The ability to create growth also depends on competitors. As the competitive environment is changing rapidly, business models also require constant improvements. Business models explain how to capture a suitable share of the value, and strong models enable firms to capture a significant portion of that value and provide firms the potential to keep or to build competi- 
tive advantage. Good and efficient business models are coherent (all the parts of the model should be in accordance with each other) and they offer competitive advantage (by building a strategic asset as a unique product, differentiated channels, information advantage) (Euchner \& Ganguly, 2014).

A significant turning point in developing an integrated definition of the business model occurred when researchers stopped directly editing a different definition of the business model; instead of this they simply did an inventory of all the components used in the definition. Osterwalder, Pigneur and Tucci (2005) have identified nine components; they later assembled a visualisation tool called 'Canvas.' We should be aware, that Canvas is not a business model, but it is only a tool that enables firms to articulate their business model.

Canvas represents the individual dimensions of the business model and their properties. With the classification of them, it reveals the determinants that apply in a competitive environment. At the same time, it provides a clear summary of the areas where improvements can be implemented and where innovations of the business model of the organisation are needed. The value for the user is situated in the centre; the right side refers to the relationship with customers, the left side with suppliers, while the lower part represents cash flows.

\section{Business Model Innovation}

Business model innovation radically changes the processes within the organisation with a view to achieving a competitive advantage or, in an extreme form, the survival of the organisation (Linder \& Cantrell, 2000). In their study, Euchner and Ganguly (2014) stated that each innovation that creates new markets or affects the competitive advantage of competitors can be understood as business model innovation. Lindgardt, Reeves, Stalk, and Deimler (2009) also said that to start talking about a business model innovation, two or more elements of business model should be changed, and the value should be delivered to customers in a new way. For Matzler, Bailom, Friedrich, and Kohler (2013), business model innovation is a result of the organisation aiming to increase customer value and thus creating a new means of value and revenue creation, enabling the organisation to capture this value.

The process of business model innovation is a complex and challenging task. Moreover, it is a systematic procedural activity that can enable the organisation to perform in new markets, with new customers, capturing different positions in the market, and offering new value to existing customers. Najmaei (2011) stated that business model innovation even extends to strategic planning and decision-making. Therefore, all processes within the organisation and the relationships with the environment, its resources and future needs should be self-evident to the individuals that are responsible for the changes and improvements in business model innovation. In addition, the knowledge and understanding of the current business model are essential to the process of business model innovation. Aiming to define the current position and possible improvements of the business model, Chesbrough (2007) proposed a framework for the classification of organisations based on the properties of their business model. According to the level of how their business model is developed, he identified six different types of firms, i.e. firms having their business model badly defined, only partially defined, segmented, opened, with innovation processes integrated, and in the form of a flexible platform.

In their study, Amit and Zott (2012) suggested to managers that they should have clear answers to some key issues before starting with implementing innovation. They should know which of the customer's problems will be resolved with a new business model, what new activities are required to solve these problems, how these activities will be related to each other, who will carry out each activity, and how the new value and revenues for stakeholders will be created through the new business model. Matzler et al. (2013) identified three types of business model innovation. First, the value is not added to the product or service, but the added value is the result of reduced costs and prices. In this case, both for the customers and for the firm the additional value is created. Second, customers are willing to pay more for innovative products or services. Third, reduced prices for a truncated product or service may present higher value for customers. 
Business Model Innovation in Tourism

Like other industry sectors, the tourism industry has also encountered a variety of changes recently. New technologies and new tourist habits are the main reasons for the constant development. In tourism, new business opportunities are emerging due to internal and external forces (Wensveen \& Leick, 2009). In addition to the emergence of the Internet, which significantly influenced the development of business models (the possibility of integrating tourists in tourism firm's processes, the facilitation of the collaboration with partners and networking, reaching customers through new channels as social media), new ways of pricing and revenue streams can also be identified (Verma \& Varma, 2003). A great number of new opportunities regarding new business models in contrast to the old ones have been created.

In the tourism sector, travel agencies are obviously conscious of the need to adapt their business model according to the current changes on the tourism market. The first step in this adaptation to the new characteristics of the tourism sector is the understanding of different dimensions in their current business model. The Canvas business model (Osterwalder \& Pigneur, 2010) by itself can provide firms options for the agencies. Aiming to make changes and improvements in their performance, travel agencies should start with the transformation of their business models.

The value proposition (for customers) is always at the heart of Canvas. This dimension is a key factor in the process of obtaining (or losing) customers. It is the foundation of the entire business model as it explains how to solve the problem of a firm's customers. By solving these problems better than their competitors do, the firm's product/service becomes more attractive. The customer segments part is about to whom the value proposition is offered. It can include different segments that exist on the market, namely private customers or business partners, students, young people, seniors, cultural travellers, adventurers, families, disabled people, a specific niche market (customers that are searching for a customised travel destination), etc. Key partners are another dimension of the Canvas business model. The customer relationships part is about how the firm is interacting with and handling customers. In recent years, especially in the tourism sector, an important role was given to the co-creation of the products/services. Channels represent all the ways to access consumers. The key activities are positioned on the supply side of the Canvas business model. They include all the activities that are undertaken by the firm with the aim of making their business model work. The key resources constitute tangible and intangible resources necessary to create and deliver value. They are divided into human, physical, intellectual, and financial. The lower part of the Canvas framework represents costs (expenses) and revenues.

\section{Methodology}

In the process of designing the interview, we paid special attention to the possibility of informal information detection during the interview. The interviewee knowingly provided us with direct information, while subconsciously he also offered information enabling credible and impartial complementary insight into the life of the organisation. This was achieved via suitably shaped main issues and intermediate sub-questions. The interviewee was not only directed but also encouraged to present a comprehensive and realistic depiction of the travel agency operations.

\section{Research Methods}

In the theoretical part, we analysed the content of previous research and used a few practical examples. Emphasis was placed on the presentation of the concept of business model and the importance and urgency of its innovation. In the empirical part, through an individual semi-structured interview with a targeted selection of a tourist agency, we covered the content that served to determine the change of business models in organisations. By analysing the interview, we thus tried to come to understand how the company is changing its business model, and how successful they are at it, regarding the implicit or explicit presence of the business model. The semi-structured interview consisted of eleven questions, the first nine of which were intended to verify the format and segments of changing the business model. The last two questions checked how this change was reflected in the success of the 
organisation. The credibility of the research was increased by the analysis of formal and informal information.

\section{Analysis and Interpretation of Data}

\section{from the Semi-Structured Interview}

The interview of the management of the organisation was carried out in a company that includes a travel agency as an autonomous unit. In the interview the head of the agency, who had a complete overview of the entire operation of the company, participated. Innovating a business model applies to all segments of the company, and because we wanted to obtain a consistent image of the changing processes within the company, we needed to obtain information about all activities. To facilitate a better interaction of the participating interviewee we decided to record the interview. Thus, in addition to a more accurate recording of content, we enabled the study of subjective experiences of the interviewee through his non-verbal feedback, which was even more pronounced due to personal acquaintance.

The information thus obtained was arranged by individual questions from the interview, referring to the Osterwalder Business Model Canvas with the nine business model building blocks. To that, we added two questions from a questionnaire, which was used to determine the position of the participating tourist agency in the study with regard to changes within the organisation.

\section{Findings}

The interview was recorded using the appropriate technical equipment, with the analysis and interpretation being performed point by point while respecting the overall context of the interview. In so doing, we reduced the impact of problems with retrieving information and their incorrect classification according to individual segments of the visualisation tool.

The agency increased the value for customers through greater transparency in supply and thus a lower risk for customers, including tourist product personalisation and greater economy of use, even though it retains the classic shape of the offer due to the average age and the informational awareness of its customers.
The practice of recent years in the foreign and domestic market confirms that for a better position in the market the customer needs to be offered more, including Web support for commerce in the otherwise rather rigid sales policies of the organisation.

Within the observation period of the previous five years, the agency was active mostly on the Slovenian market. The Italian market had no relevant share. With the onset of the economic crisis, this ratio began to change. The number of individual customers was diminishing, and the lower standard of living caused a drastic reduction in the volume of the middle segment. Therefore, they shifted to the segment of firms, groups and societies, and particularly to the Italian market. Due to the new situation in the Slovenian market, the direction toward acquiring new customers from abroad was a logical step, as the latter have greater economic potential than the Slovenian market does. The segment was further changed by reducing their own sales via the distribution network of other agencies. At the onset of the crisis, the agency was forced to radically innovate the customer segment. This was of existential importance to them; without it, they would have had a difficult time surviving.

The agency changed the key partners segment to a lesser extent, but the change was still noticeable. The reason for the change was to expand into foreign markets as well as the need to create higher added value and bring higher value to the user in the form of higher quality products. Particular significance can be attributed to the last statement about the necessity of change, as this declaration is repeated in a similar form throughout the entire interview.

In the field of travel agencies, the customer relationship dimension of the business model is somewhat specific. In the short term, it is important to maintain existing customers and to promote sales of more expensive products, as well as to promote the increase in the frequency of purchase. The agency was thinking in the direction of enhancing the quality of the product itself, which would, in turn, bring higher prices, and was keen on increasing sales volume. From a longterm perspective, it is unquestionably only important to acquire new customers; in this respect, they placed high hopes on the Italian market. We noted that previ- 
ously there had been no need for this. Nowadays they strive toward long-term stable operations; thus, they are aware of the importance of the activity of maintaining the existing customers as well as of acquiring new ones. Existing customers have received considerable attention; however, they are aware that this attention will someday cease.

They include customers in the co-creation of tourism products from the initial formation of the product onward. Particular emphasis is placed on closed groups, where the greatest involvement of customers is present. They started to change this part of the customer segment upon entering the Italian market. On the Slovenian market, similar changes were carried out mainly with the purpose of reducing the dissatisfaction of the Slovenian customers who, despite the lower prices, expected the same level of services. The interviewees ascribed great importance to the customers' involvement in creating a better product; however, we noted through our interview that this was an advantage that they neither knew how to present nor how to advertise.

It may be noted that the agency changed the customer relationship dimension because of the better harmony with other business model dimensions as well as due to external changes. In the past, they had used the concept of customer's co-creation of products; it now was being used on a larger scale.

Because of the higher average age of the customers, the main distribution channel remains face to face contact. New opportunities for channels via the World Wide Web did not significantly affect the operations in the agency. The agency always practiced direct interaction with its customers. The Internet works well for the so-called 'tendered trips', by which a certain number of arrangements is prepared and offered for sale. We noted that in this case the communication channel of direct mail was very effective. With a view to long-term stability, they are preparing changes to place greater emphasis on intensive online sales. They are also preparing the introduction of loyalty cards.

Thus, the distribution channels, depending on the specificity of the agency's operations in a specific environment, have not changed significantly. However, we noted that certain changes have been made and that the agency was working on some major changes in the future.

We found that the key activities of the agency did not change and that tourism products remained a 'core business.' The agency was focused on tourism and the form of offer did not change. This was also the position of the organisation's management as, in accordance with the main orientation, the tourist industry supported the core capabilities of the organisation.

Among the key activities, the 'identity trap' phenomenon was dominating. The organisation's management did not see the need for new key activities, and they took even less fondly to the chance that these new activities could be used in the role of core capabilities. This example confirmed, as had also been shown by our previous study (Ambrož, 2015), the rule that this segment is the most neglected one in most cases of business model innovation.

Regarding key resources, only one new employee had been hired. This made it easier for them to cope with the increased workload. The new employee had a license to use the central reservation system. Regarding the financial resources, there had been no change. In the past, they tried to pass the risk of indebtedness on to the consumers with the help of credit cards, but that did not work out. The change of key partners has enabled much shorter periods of advance payments and in some cases even the possibility of paying after the related service has been provided. Therefore, this segment has not experienced significant changes. Stable staffing is not always positive, since it represents the basis for the aforementioned trap of identity. Here, too, the paradigm of the absence of employee training is dominating because the costs would not allow it. Although human resources and their competence are crucial for an organisation, the training of employees is, in most cases, absent from the Slovene environment.

Due to the nature of operations, the variable costs are the most significant. The fixed costs represent a lesser impact. The price of the products was largely controlled by the managing of variable costs. The fixed costs proved a slight increase at the level of the agency but only due to an additional employee, and consisted of labour costs and rental costs. We noted that major 
changes in this costs structure were not implemented. This segment in the agency was relatively stable. We assumed that the absence of the need to amend this segment, thereby optimising the business activities, was due to stable operations.

At the beginning of the observation period, the majority of customers were families; thus, there were many payments in cash. The agency wanted to minimise the share of the cash payments; therefore, the majority of invoices were paid through the bank. The transition from the cash payments means less time spent at the cash register and less chance of error. In the future, they want to eliminate cash payments. Dynamic pricing depending on the tourist season is an established practice in the travel industry. In addition, they wanted to implement further changes with dynamic pricing at the daily level; however, they are limited by Slovenian legislation. More specifically, they are limited by administrative obstacles and are not allowed to change the prices quoted during the day. Their aim to introduce dynamic price changing was thus hindered by administrative barriers.

Changes regarding the revenues stream were seen as a reactive adaptation to the changing market conditions as well as the desire for a more proactive approach to enhance competitiveness. The absurdity of this was that the agency wanted to introduce changes, but they were not able to do so because of legislative restrictions.

\section{Discussion, Limitations, and Assumptions}

Many studies have focused on how business model thinking can be employed in entrepreneurial startups; however, it can also be used as an opportunity for managerial thinking in established firms (BadenFuller \& Mangematin, 2013). Doing so, we found new insights into how a tourist agency innovates its business models to adapt to new market challenges. In a previous study (Ambrož, 2015), it was found that some organisations could survive without introducing any changes and without major consequences. Such cases were seen as possible only because of the absence of competition in the local environment and the rigidity of such environments. Most organisations were convinced that without the innovation of individual seg- ments of the business model, or more often the majority of its dimensions, they would no longer exist. Also in our case of the tourist agency, the necessity of innovating the business model was confirmed by the statement of the agency's manager: 'In any case, without changes, we would no longer exist on the market; without future changes, we will no longer exist either.'

We noted that the implemented changes were extremely urgent and of key importance. The agency was aware that changes - of course, if they want to remain competitive and survive - will also be indispensable in the future.

The agency has discovered hidden resources in additional competencies. They also found that their digital platform allowed for an incomparably greater dynamic in adapting their offers for the customer. This is especially true for the tourism sector, where customers require rapid and effective solutions. In addition, they also found that a different organisational form (for example, the dynamic allocation of tasks) would increasingly support various demands from customers.

The agency manager is well aware of the direct and indirect benefits of changes and stressed that the latter were essential. This enabled them to survive, to remain competitive, and to justify the starting point for further changes, for the gradual relocation of part of their business to the field of digital technologies. Significant benefit was observed in the necessity of certain changes, which made it easier to change the segments that did not necessarily need changing. In fact, the business model innovation comprises a variety of incremental modifications that improve a firm's performance (Martins, Rindova, \& Greenbaum, 2015).

This research was based on several assumptions. The first assumption was that an organisation wants to be competitive, which represents the basis for its long-term survival in the market. Therefore, we chose a travel agency with a locally prominent role and a long tradition. Another assumption was that the business environment is constantly changing. In this case, an organisation needs to change along with it. The study included certain methodological and substantive limitations in addressing the problem. The first limitation is the internal validity of the information, which is analysed on the basis of subjectively shaped pat- 
terns and categories of that qualitative analysis of interviews. Moreover, substantive limitations cannot be avoided due to the choice of the organisation. To improve the credibility of the research findings, we would need a larger sample of companies, which would exclude the impact of the extensive general economic crisis in Slovenia. Finally, one of the problems was also the recollection of changes made within the organisation by the participant in the survey, which was in the interpretation partially mitigated by searching for patterns in the context of the entire interview.

\section{Implications for Practice and Consequences}

The key finding of our research is that many organisations are not aware of their business model; moreover, they have never articulated it. Chesbrough (2007) stressed that the business model is always present in an organisation whether it is articulated or not. The most important conclusion for the practice is that the organisations must articulate their business models first and then innovate them. There is no need for high technology to drop out of existing business models or even ways of thinking and there are no limits regarding the industry. The tourism industry is not an exception. In every industry, organisations can innovate and overtake their competition if they will step into customer's shoes, rethink their existing way of business and discover new ways of delivering added value to their customers.

Managers in tourism firms should use their business models to identify the values of their products and what their customers are willing to pay for. They must find ways to make money and evaluate costs in the value creation process. It is necessary for the company to realise who their most essential customers are, how to reach them and what the most appropriate way of communication with them is.

The Canvas business model should be applied to all tourism companies. We have proved that it is a useful tool when analysing the performance of the organisations. Furthermore, as the tourism industry is constantly confronting global changes, companies are forced and obliged to innovate and thus to change their business models. The Canvas business model can be used for the analysis of the state of art in the company as well as in the process of developing new business concepts. Moreover, it should serve as support in the decision-making processes.

\section{Conclusion}

How can we measure the extent of change and recognise whether we have made significant changes or not, if we only have subjective judgment? Is the change of the customers' profile of the agency large or small? Is it also possible to realise that some changes do not mean innovation of the agency business model? Our case is particularly interesting because we have (1) demonstrated the interdependence of segments and their modifying, (2) observed that innovation of business model lead to new revenue streams and thus to survival and competitiveness, (3) showed that the business model is already present in tourist agency and we articulated it, (4) presented the necessity of changing the business model that is inherent to an organisation in order to maintain competitiveness, (5) identified changes that are drastic for some companies in their business, (6) emphasised the relativity of the scope of changes (e.g. ratio between direct/indirect sales, change payment methods, etc.). In our case of the tourist agency, the necessity of innovating the business model was confirmed by the statement of the agency's manager: 'In any case, without changes, we would no longer exist on the market; without future changes, we will no longer exist on the market either.'

\section{References}

Ambrož, R. (2015). The importance of innovation business model in achieving competitiveness (Unpublished master thesis). University of Primorska, Koper, Slovenia.

Amit, R., \& Zott, C. (2012). Creating value through business model innovation. MIT Sloan Management Review, 53(3), 41-49.

Baden-Fuller, C., \& Mangematin, V. (2013). Business models: A challenging agenda. Strategic Organization, 11(4), 418427.

Casadesus-Masanell R., \& Ricart, J. E. (2010). From strategy to business models and onto tactics. Long Range Planning, 43, 195-215.

Casadesus-Masanell, R., \& Heilbron, J. (2015). The business model: Nature and benefits (Working Paper No. 15-089). Harvard Business School, Boston, MA. 
Chesbrough, H. (2007). Business model innovation: It's not just about technology anymore. Strategy \& Leadership, $35(6), 12-17$.

Chesbrough, H., \& Rosenbloom, R. S. (2002). The role of the business model in capturing value from innovation: Evidence from Xerox corporation's technology. Industrial and Corporate Change, 11(3), 529-555.

Euchner, J., \& Ganguly, A. (2014). Business model innovation in practice: A systematic approach to business model innovation can help capture value and reduce risks. Research-Technology Management, 57(6), 33-39.

Gebauer, J., \& Ginsburg, M. (2003). The us wine industry and the Internet: An analysis of success factors for online business models. Electronic Markets, 13(1), 59-66.

Linder, J., \& Cantrell, S. (200o). Changing business models: Surveying the landscape. Cambridge, MA: Accenture Institute for Strategic Change.

Lindgardt, Z., Reeves, M., Stalk, G., \& Deimler, M. S. (2009). Business model innovation: When the game gets tough, change the game. Retrieved from: https://www.bcg.com/ documents/file36456.pdf

Magretta, J. (2002). Why business models matter. Harvard Business Review, 8o(5), 86-92.

Martins, L. L., Rindova, V. P., \& Greenbaum, B. E. (2015). Unlocking the hidden value of concepts: A cognitive approach to business model innovation. Strategic Entrepreneurship Journal, 9(1), 99-117.

Matzler, K., Bailom, F., Friedrich, S., \& Kohler, T. (2013). Business model innovation: Coffee triumphs for $\mathrm{Ne}$ spresso. Journal of Business Strategy, 34(2), 30-37.

Najmaei, A. (2011, 19-21 August). Dynamic business model innovation: An analytical archetype. Paper presented at the 3 rd International Conference on Information and Financial Engineering IPEDR, Shanghai, China.
Osterwalder, A., \& Pigneur, Y. (2010). Business model generation. Hoboken, $\mathrm{N}$ : Wiley.

Osterwalder, A., Pigneur, Y. \& Tucci, C. L. (2005). Clarifying business models: Origins, present, and past future of the concept. Communications of the Association for Information Systems, 16, 1-25.

Teece, D. J. (2010). Business models, business strategy and innovation. Long Range Planning, 43(2-3), 172-194.

Tikkanen, H., Lamberg, J. A., Parvinen, P., \& Kallunki, J. P. (2005). Managerial cognition, action and the business model of the firm. Management Decision, 43(5/6), 789809.

Timmers, P. (1998). Business models for electronic markets. Electronic Markets, 8(2), 3-8.

Verma, D. P. S., \& Varma, G. (2003). On-line pricing: Concept, methods and current practices. Journal of Services Research, 3(1), 135-155.

Zott, C., Amit, R., \& Massa, L. (2010). The business model: Theoretical roots, recent developments, and future research (Working Paper w P-862). University of Navarra, IE SE Business School, Barcelona, Spain.

Yip, G. S. (2004). Using strategy to change your business model. Business Strategy Review, 15(2), 17-24.

Yunus, M., Moingeon, B., \& Lehmann-Ortega, L. (2010). Building social business models: Lessons from the Grameen experience. Long Range Planning, 43(2/3), 308-325.

Wensveen, J. G., \& Leick, R. (2009). The long-haul low-cost carrier: A unique business model. Journal of Air Transport Management, 15(3), 127-133.

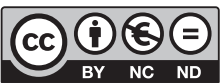

This paper is published under the terms of the Attribution- NonCommercial-NoDerivatives 4.0 International (CC BY-NC-ND 4.0) License. 